\title{
In Reply: Prophylactic "First-Step" Central Neck Dissection (Level 6) Does not Increase Morbidity After (Total) Thyroidectomy
}

\author{
Andreas Selberherr, MD, Philipp Riss, MD, Christian Scheuba, MD, and Bruno Niederle, MD \\ Section of Endocrine Surgery, Division of General Surgery, Department of Surgery, Medical University, Vienna, Austria
}

\section{TO THE EDITORS}

Thank you for the letter by I.J. Nixon to our article. ${ }^{1}$ Some of his critical comments have to be clarified.

This is a single-centre, technical report demonstrating the possible advantage of "first step" (FS) and therefore prophylactic uni- and bilateral central neck dissection (CND) if indicated. As stated by Carty et al. in the consensus statement on the terminology and classification of CND for thyroid cancer, we defined the boundaries of the central neck superiorly by the hyoid bone, laterally by the carotid arteries, anteriorly by the superficial layer of the deep cervical fascia, and posteriorly by the deep layer of the deep cervical fascia. ${ }^{2}$ Also, the lymphatic tissue of the anterior superior mediastinum, which is accessible by a cervical approach, was removed by the described approach.

The controversies regarding whether to perform prophylactic CND to improve survival or to prevent local recurrence were not discussed in the manuscript. ${ }^{3}$

Concerning the effect of prophylactic CND on locoregional recurrence rates, the meta-analysis by Wang et al. revealed no difference in recurrence or long-term compli- cation rates between patients undergoing total thyroidectomy alone or total thyroidectomy with (prophylactic) CND. ${ }^{4}$ In accordance with our study, Wang et al. concluded on the basis of their meta-analysis that routine prophylactic CND might be considered in the hands of high-volume surgeons treating patients with clinically node-negative PTC. ${ }^{1,4}$

\section{REFERENCES}

1. Selberherr A, Riss P, Scheuba C, Niederle B. Prophylactic "firststep" central neck dissection (level 6) does not increase morbidity after (total) thyroidectomy. Ann Surg Oncol. 2016;23(12): 4016-22.

2. Carty SE, Cooper DS, Doherty GM, et al. Consensus statement on the terminology an d classification of central neck dissection for thyroid cancer. Thyroid. 2009;19(11):1153-58.

3. Clayman GL, Agarwal G, Edeiken BS, Waguespack SG, Roberts DB, Sherman SI. Long-term outcome of comprehensive central compartment dissection in patients with recurrent/persistent papillary thyroid carcinoma. Thyroid. 2011;21(12):1309-16.

4. Wang TS, Cheung K, Farrokhyar F, Roman SA, Sosa JA. A metaanalysis of the effect of prophylactic central compartment neck dissection on locoregional recurrence rates in patients with papillary thyroid cancer. Ann Surg Oncol. 2013;20(11):3477-83.

(C) Society of Surgical Oncology 2017

First Received: 13 October 2017;

Published Online: 27 October 2017

A. Selberherr, MD

e-mail: andreas.selberherr@meduniwien.ac.at 